\title{
Evaluation of interfacial bond strength between Portland cement concrete and asphalt concrete layers using bi-material SCB test specimen
}

\author{
M. M. Mirsayar ${ }^{a^{*}}$, X. Shi ${ }^{\mathrm{a}}$ and D. G. Zollinger ${ }^{\mathrm{a}}$
}

${ }^{a}$ Texas A\&M University, Zachry Department of Civil Engineering, College Station, TX 77843-313, USA

\begin{tabular}{|c|c|}
\hline A R T I C L EI N F O & A B S T RACT \\
\hline $\begin{array}{l}\text { Article history: } \\
\text { Received } 6 \text { April, } 2017 \\
\text { Accepted } 3 \text { August } 2017 \\
\text { Available online } \\
\text { 3 August } 2017\end{array}$ & $\begin{array}{l}\text { Portland cement concrete (PCC) / asphalt concrete (AC) bonded components are seen in both } \\
\text { conventional pavement structures as well as overlays. Due to the environmental and traffic } \\
\text { loads, cracks occur at the interface of the PCC and AC layers and finally, may propagate } \\
\text { through the interface or one of the layers. Therefore, the evaluation of bond strength between }\end{array}$ \\
\hline $\begin{array}{l}\text { Keywords: } \\
\text { Bi-material SCB specimen } \\
\text { Interfacial bond strength } \\
\text { Cement/asphalt interface } \\
\text { Experimental study } \\
\text { Fracture theory }\end{array}$ & $\begin{array}{l}\text { these layers is important. This paper investigates bond strength between asphalt concrete and } \\
\text { Portland cement concrete using a new sandwich test specimen. The developed specimen, called } \\
\text { Bi-material semi-circular bend (BSCB) is made of asphalt concrete and the Portland cement } \\
\text { concrete, cracked at the interface of the materials. First, the suggested specimen is introduced } \\
\text { and characterized using finite element simulation. Then, the specimen is employed to obtain } \\
\text { bond strength between asphalt concrete and Portland cement concrete under mixed mode } \\
\text { loading, and at two temperatures: -20C and 20C. The fracture toughness at different mixed } \\
\text { mode conditions is obtained, and finally, fracture criterion for the tested bonded joints is } \\
\text { presented. }\end{array}$ \\
\hline
\end{tabular}

\section{Introduction}

Bonded layers can be seen as a part of many industrial and engineering structures. In pavement industry, the white topping rehabilitation technique has recently been explored by many U.S. Departments of Transportation (DOTs) whereby a relatively thin layer of concrete is applied over a prepared asphalt concrete base. As noted in the literature, an interface crack may occur between the pavement layers, mainly due to the external environmental induced movements, that propagate and delaminate the layers. Bonded joints are not limited to the pavement engineering application and are widely used in other engineering structures. For example, bonding components made of concrete/rock, silicon/glass, ceramic/metal and composite/metal are extensively used in civil engineering structures, electronic devices, automobiles and aircrafts (Yang et al., 1998; Chaudhuri \& Chiu, 2007; Chandra Kishen \& Singh, 2001; Wang et al., 2013; Dunn et al., 2000). At the interface of all bi-material * Corresponding author.

E-mail addresses: mirmilad@tamu.edu (M. M. Mirsayar) 
components, cracks may create as a result of imperfect bonding or during the service life of the structures containing these bonds. The interface cracks are often subjected to mixed mode loading conditions, because of the asymmetry in material property at the interface, and they may propagate through the interface, or may kink into one of the materials in the strong interfaces (e.g. Arabi et al., 2013; Ayatollahi \& Mirsayar, 2011; Ayatollahi et al., 2010a,b; Ayatollahi et al., 2011; Chandra Kishen \& Singh, 2001; Dunn et al., 2000; Mirsayar, 2013, 2014a, b, c; Mirsayar \& Park, 2016a; Mirsayar \& Samaei, 2013, 2014, 2015).

Several theoretical and experimental methods have been explained by researchers in the past to investigate mechanism of crack propagation through different materials (e.g. Ambati et al., 2015; Ayatollahi et al., 2013; Lazzarin and Zambardi, 2001; Miehe et al., 2015; Maiti \& Smith, 1983; Mirsayar 2015a, b; Mirsayar \& Park 2016b; Aliha et al. 2012; Mirlohi \& Aliha 2013; Mirsayar et al. 2016a; Mirsayar, 2017; Mirsayar et al. 2017a, b; Sih \& Macdonald, 1974). While the experimental fracture studies on real components are often expensive and difficult, researchers prefer to conduct their experiments on laboratory specimens. However, appropriate fracture criteria are also required to correlate the experimental results obtained from the simple laboratory specimens to the fracture event in cracked structures under their complex service loading conditions (Mirsayar \& Takabi, 2016). In order to validate a fracture criterion, researchers have to conduct a series of fracture tests on appropriate test materials by using suitable test specimens. For mixed mode fracture tests, a suitable test configuration should have simple geometry and loading conditions, inexpensive preparation procedures, convenience of testing set up, and also the ability of addressing both mode I and mode II failure conditions. Some of the test configurations proposed in the literature investigating mixed mode I/II fracture are briefly described here. Erdogan \& Sih (1963), Williams \& Ewing (1972) and Theocaris (1984) used a rectangular plate containing an inclined center crack subjected to a uniform far field tension in their mixed mode fracture studies. The symmetric and asymmetrically loaded three or fourpoint bend specimens were also employed by researchers for investigating mode I and mixed mode brittle fracture (Fett et al., 1995; Xeidakis et al., 1996; Suresh et al., 1990, Aliha et al. 2009; Razavi et al., 2017, Aliha \& Bahmani 2017; Bahmani et al. 2017; Heidari-Rarani et al., 2014), Disc type specimens including the centrally cracked Brazilian disk (BD) specimen, centrally cracked/notched ring specimen subjected to diametrall compression, edge notch disc bend (ENDB) and the semi-circular bend (SCB) specimen have been frequently employed for determining the mixed mode fracture resistance of various engineering materials such as rocks, graphite, concretes and polymers (Awaji \& Sato, 1978; Ayatollahi et al., 2006; Ameri et al. 2012,2016; Razmi \& Mirsayar, 2017; Alhasan 2013; Fakhri et al. 2017, Aliha et al. 2008,2014,2015a,c, 2017, Abd-Elhady 2013; Al-Hdabi et al. 2014; Dehghany et al. 2017, Bahmani et al. 2017). However, some of these specimens have certain shortcomings. For example, some of the mixed mode test configurations are able to provide only limited mode mixities or require complicated loading fixtures.

In a bi-material fracture test specimen, the stress intensity factors are influenced by the mechanical properties of each material as well as the specimen geometry (e.g. Ayatollahi et al., 2010a, b; Mirsayar, 2014a; Mirsayar et al., 2014; Mirsayar \& Park, 2015, Mousavi \& Aliha 2016). However, for a conventional fracture test specimen made of a single material, the specimen can be characterized only by its geometry. In other words, one should choose a bi-material fracture test specimen based on both specimen geometry as well as the material properties of each material. Some of the test configurations proposed in the literature for investigating mixed mode I/II fracture of bonded structures are briefly described in the following. Charalambides et al. (1989) suggested a new four-point bend specimen for measuring the fracture resistance of bi-material interfaces. Utilizing a finite element approach, they characterized their suggested specimen and calculated stress intensity factors at different specimen geometries and elastic properties. They demonstrated the utility of their specimen by conducting tests on Al/PMMA bonded joints. However, their suggested specimens were not able to cover all mixed mode conditions that range between pure mode I and pure mode II. Evans et al. (1989) studied the interface crack propagation in different bi-material fracture test specimens including Sandwich test specimens, Peel test specimens, de-cohesion test specimens, and composite cylinder test specimens. They demonstrated that the choice of test specimen governs the tendency of cracks to either remain at 
the interfaces or deviate away, depending on the specimen geometry. However, none of the mentioned specimens were able to cover all mixed mode conditions.

The specimens of circular or semi-circular shape (SCB) are very suitable for fracture testing on rock or asphalt materials because they can be easily cored from pavement. However, the SCB specimen has not been used so far for any bi-material testing to evaluate bond strength. In this paper, a bi-material SCB (BSCB) test specimen is investigated for fracture test of asphalt concrete (AC) / Portland cement concrete (PCC) bonded layers. The BSCB specimen is further described along with its capabilities and advantages by means of finite element analysis. Following this discussion, the BSCB specimen is used to evaluate tensile, shear, and mixed tensile/shear bond strength between Portland cement concrete and asphalt concrete.

\section{Objective of the research}

As illustrated in Fig. 1, a concrete slab curls upwards as a result of environmentally induced strain profile throughout the slab. The end movements in concrete slab, shown in Fig. 1, is the first step towards erosion damage which is a distress type that threatens the sustainability of a concrete pavement, and thus, needs to be controlled. The bond strength between the PCC and AC layers significantly influences on the vertical and horizontal end movements in concrete slab. The slab lift-off is accompanied by occurring and propagation crack at the interface of two layers, as shown in Fig. 1.

As investigated by Mirsayar et al. (2016b), the interfacial fracture mechanics can be utilized successfully to describe delamination of the pavement layers. An interface crack can be characterized by the stress intensity factors. In other words, one can characterize the interfacial bond strength between the PCC and AC layers by evaluating stress intensity factors of the interface crack. On the other hand, the critical bond strength is affected by many factors which influence on the chemical bond behavior between the layers. One of the most important factors is the temperature in which the delamination occurs. The objective of this paper is 1) introduce bi-material SCB test configuration (BSCB) for evaluation of bond strength of different bonded layers under tensile, shear, and combination of tensile/ shear loads; 2) evaluating the bond strength between the PCC and AC at two different temperatures. The bond strength between the PCC and AC layers is evaluated using interfacial stress intensity factors. The fracture tests are conducted on BSCB specimens, made of PCC and AC, at $+20 \mathrm{C}$ and $-20 \mathrm{C}$ temperatures to cover an applicable range of in-service pavement temperature. Finally, failure criteria and mixed mode fracture toughness are presented for the test data obtained at both temperatures.

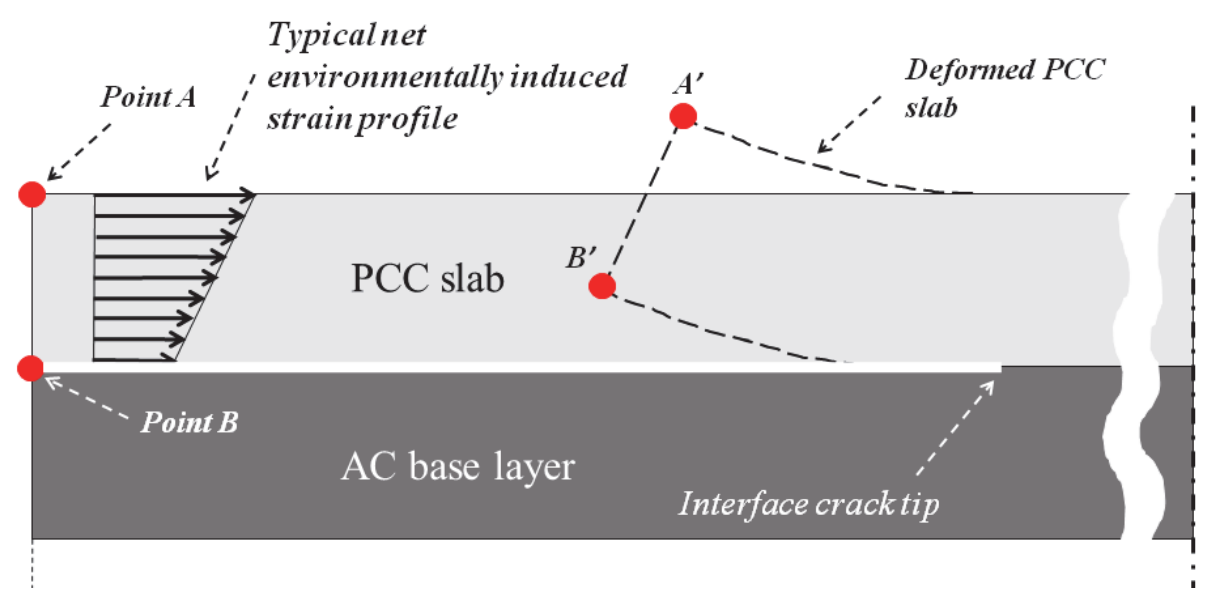

Fig. 1. General configuration of concrete slab on the asphalt pavement base layer

\section{New test configuration}

The classical semi-circular bend (SCB) specimen has been used by several researchers in the past for investigating mixed mode fracture in brittle materials, (e.g. Ayatollahi et al., 2006; Lim et al., 1994). The SCB specimen typically contains an angled crack and is subjected to three-point bending. Fig. 2 shows the geometry and loading conditions for the bi-material SCB test specimen (BSCB), introduced 
in this paper, for examination of the mixed mode propagation of a crack along the interface of two dissimilar materials. In this test specimen, a semi-circular specimen of radius $\mathrm{R}$ that contains an edge interface crack of length a with inclination angle of $\delta$, is loaded asymmetrically by a three-point bend fixture. As illustrated in Fig. 2, the crack exists at the interface of AC and PCC. While the specimen is easily manufactured, it does not need complicated loading fixtures for using in conventional testing machines. The state of mode mixity in the BSCB specimen can be easily altered by changing the locations of two bottom supports (S1 and S2) and the crack inclination angle ( $\delta$ ). The mode I and mode II contributions can be controlled simply by choosing appropriate values for S1, S2, and $\delta$. Hence different mode mixities can be obtained in the BSCB specimen. The specimen has been frequently used in the past but only for the simple case of homogeneous material (single material) in order to obtain fracture toughness for several engineering materials including, rocks, concrete, asphalt, polymers, etc. (Ayatollahi et al., 2006; Lim et al., 1994; Li \& Marasteanu, 2005, Aliha \& Fattahi Amirdehi 2017, Aliha et al. 2012,2015b, Aliha \& Ayatollahi 2013).

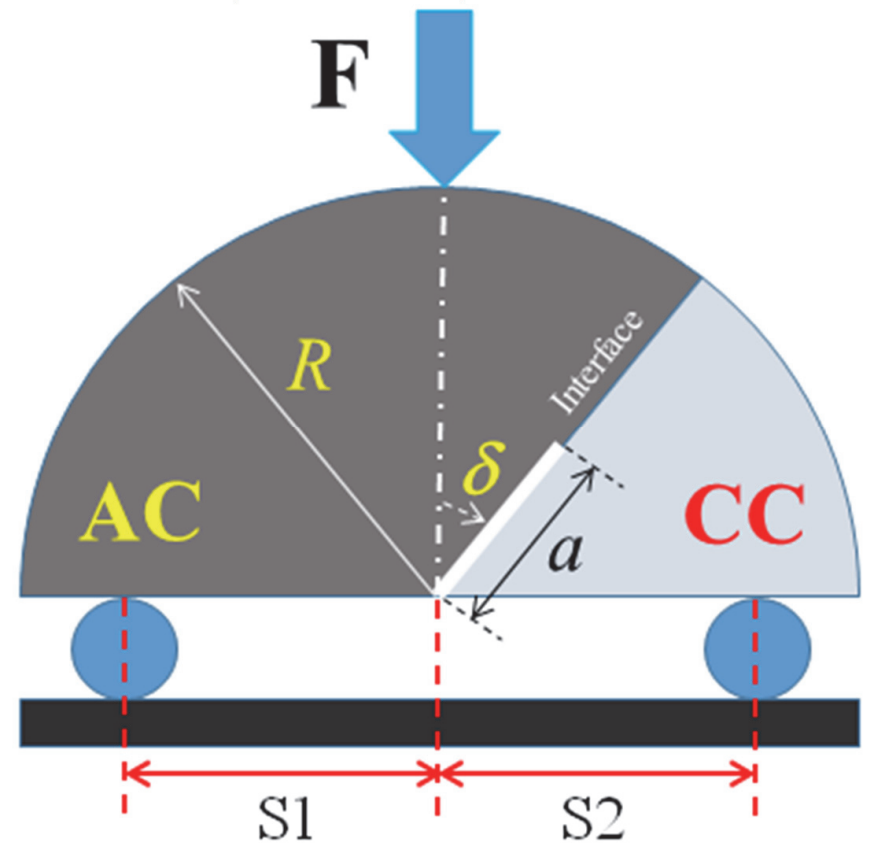

Fig. 2. Scheme of the BSCB specimen made of asphalt concrete and Portland cement concrete

In order to evaluate tensile/ shear bond strength between the PCC and AC using interfacial fracture mechanics concepts, it is necessary to define the state of mode mixity by calculating the mode I and mode II stress intensity factors $\left(\mathrm{K}_{\mathrm{I}}\right.$ and $\left.\mathrm{K}_{\mathrm{II}}\right)$ for different loading positions and crack lengths. The finite element method was employed in this research to determine $\mathrm{K}_{\mathrm{I}}$ and $\mathrm{K}_{\mathrm{II}}$ in the BSCB specimen.

\section{Calculation of the stress intensity factors}

The stress intensity factors $\mathrm{K}_{\mathrm{I}}$ and $\mathrm{K}_{\mathrm{II}}$ for the BSCB specimen are functions of the crack length (a), crack inclination angle $(\delta)$, the locations of loading supports defined by S1 and S2, and elastic properties of both bonded materials. For a given material property, the stress intensity factors can be expressed as the following normalized form:

$$
\begin{aligned}
& K_{I}=\frac{F}{2 R t}(\sqrt{\pi a}) Y_{I}\left(\delta, \frac{a}{R}, \frac{S 1}{R}, \frac{S 2}{R}\right) \\
& K_{I I}=\frac{F}{2 R t}(\sqrt{\pi a}) Y_{I I}\left(\delta, \frac{a}{R}, \frac{S 1}{R}, \frac{S 2}{R}\right)
\end{aligned}
$$

where $t$ is the specimen thickness and $Y_{I}$ and $Y_{\text {II }}$ are the geometry factors corresponding to mode I and mode II, respectively. For calculating $\mathrm{Y}_{\mathrm{I}}$ and $\mathrm{Y}_{\mathrm{II}}$, different finite element models of the BSCB specimen were analyzed using the finite element code ABAQUS. Details on equations 1 and 2 can be found in 
Mirsayar (2014). In the models, the following geometry and loading conditions were considered: $\mathrm{R}=$ $76.2 \mathrm{~mm}, \mathrm{t}=25 \mathrm{~mm}, \mathrm{a}=38.1 \mathrm{~mm}, \mathrm{~F}=1000 \mathrm{~N}$ and different values for crack inclination angles $(\delta), \mathrm{S} 1$, and $\mathrm{S} 2$. It should be mentioned that according to equations 1 and 2, the calculated value for the stress intensity factors can be obtained once the finite element simulation is performed in any external load, $\mathrm{F}$, by a simple multiplication of $\mathrm{F}_{\mathrm{cr}} / 1000$ to the numerical results, where $\mathrm{F}_{\mathrm{cr}}$ is the ultimate fracture load. Since the original goal of the current research is to evaluate bond strength AC and PCC layers, in this research, we have used these two materials for finite element simulations. Same procedure can be done for any combination of the materials. The elastic properties used for the finite element modeling of the asphalt concrete and Portland cement concrete are: $\mathrm{E}_{\mathrm{asph}}=4.9 \mathrm{GPa}, \mathrm{v}=0.35, \mathrm{E}_{\text {conc }}=40.7 \mathrm{GPa}, v=0.2$. Fig. 3 shows mesh patterns generated for simulating the BSCB specimen as well as the von Mises stress contour plot for two different mode mixities: pure mode I $\left(\mathrm{K}_{\mathrm{II}}=0\right)$ and pure mode II $\left(\mathrm{K}_{\mathrm{I}}=0\right)$. In pure mode I, the stress contour is symmetric relative to the crack plane. However, because of the material mismatch, the stress contour is discontinuous at the interface. For pure mode II, the contour plot is asymmetric with respect to the crack plane showing the significant effect of shear stress. The singular elements were considered in the first ring of elements surrounding the crack tip for producing the square root singularity of stress/strain field. A J-integral based method built in ABAQUS was used for obtaining the stress intensity factors directly from software.

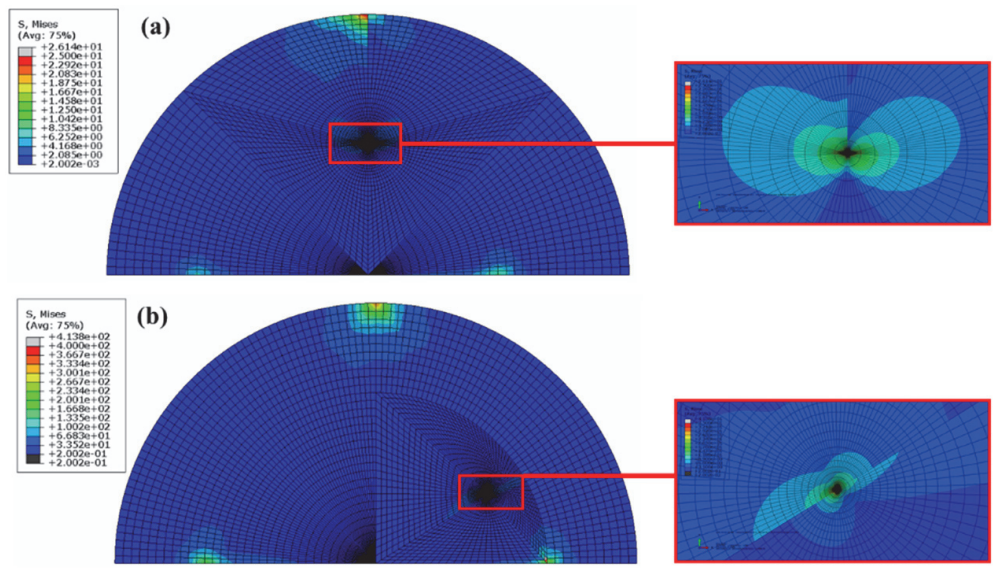

Fig. 3. Mesh pattern of the BSCB specimens as well as plots of von Mises stress contours in front of the interface crack tip at a) pure mode I, b) pure mode II conditions

Table 1 lists the values of $\mathrm{Y}_{\mathrm{I}}$ and $\mathrm{Y}_{\mathrm{II}}$ associated with pure mode I, pure mode II and three mixed mode conditions. It is seen that the proposed specimen is able to cover different mixed mode conditions from pure mode I $\left(\mathrm{M}^{\mathrm{e}}=1\right)$ to pure mode II $\left(\mathrm{M}^{\mathrm{e}}=0\right)$.

Table 1. Finite element simulation results of BSCB at different mixed mode conditions

\begin{tabular}{llllllll}
\hline $\mathrm{a}(\mathrm{mm})$ & $\delta(\mathrm{deg})$ & $\mathrm{S} 1(\mathrm{~mm})$ & $\mathrm{S} 2(\mathrm{~mm})$ & $\mathrm{Y}_{\mathrm{I}}$ & $\mathrm{Y}_{\text {II }}$ & $\mathrm{M}^{\mathrm{e}}$ & \\
\hline 38.1 & 0 & 50 & 38 & 0.323 & 0.000 & 1.00 & (pure mode I) \\
38.1 & 0 & 30 & 20 & 0.154 & 0.062 & 0.758 & \\
38.1 & 0 & 60 & 15 & 0.149 & 0.120 & 0.569 & \\
38.1 & 45 & 50 & 50 & 0.105 & 0.154 & 0.382 & \\
38.1 & 58 & 50 & 50 & 0 & 0.1 & 0 & (pure mode II) \\
\hline
\end{tabular}




\section{Specimen preparation}

A total number of $50 \mathrm{BSCB}$ specimens, made of $\mathrm{AC}$ and $\mathrm{PCC}$, were manufactured at different thicknesses ranging from $30 \mathrm{~mm}$ to $35 \mathrm{~mm}$. The raw materials used to manufacture the BSCB specimens made of AC and PCC are given as follows. For AC, PG 64-22 asphalt binder was used and the optimum asphalt binder content was $4.4 \%$ of the total weight. The asphalt binder was suplied from Jebro, Inc, Sioux City, IA. Course aggregates and sands were used to be mixed with asphalt binder. The collected ingredients were dried in an oven, sampled and used for sieve analysis to obtain the percentage of aggregates according to the standard size ranges. The aggregate gradation chart for this mix is given in Table 2. The raw materials of sand and aggregates were obtained from Knife River Corporation, Bryan, TX.

Table 2. Aggregate gradation for AC part of BSCB specimens

\begin{tabular}{ccc}
\hline Sieve size $(\mathrm{mm})$ & Standard sieve size & Percent passing \\
\hline 19 & $3 / 4$ in & 100 \\
12.5 & $1 / 2$ in & 95 \\
9.5 & $3 / 8$ in & 82 \\
4.75 & No.4 & 55 \\
2.36 & No.8 & 34 \\
1.18 & No.16 & 22 \\
0.6 & No.30 & 16 \\
0.3 & No.50 & 12 \\
0.15 & No.100 & 6 \\
0.75 & No.200 & 5 \\
0 & & 0 \\
\hline
\end{tabular}

The following combination of raw materials for the PCC were used as listed in Table 3. Coarse and fine aggregate and cement were all added to the mixer and were pre-mixed prior to adding water. Once the cement-aggregate mixture was uniformly distributed, a combination of water and admixture (see Table 3) was then added.

Table 3. Mix design for PCC part of BSCB specimens

\begin{tabular}{lc}
\hline Materials & Weight (lbs) per cubic yard of concrete \\
\hline Cement Type II & 423 \\
Fly Ash Class F & 141 \\
Coarse Agg. \#57 Crushed LS & 1850 \\
Fine Agg. Concrete Sand & 1184 \\
Water & 242.6 \\
Water Reducer Type A/D & $23 \mathrm{oz}$ \\
Air Entraining Agent & $1.7 \mathrm{oz}$ \\
\hline
\end{tabular}

Fig. 4 depicts the procedure for manufacturing the BSCB specimens. As shown in Fig. 4, the asphalt concrete portions were made first, were split into two pieces, and then placed in cylindrical molds so the concrete in a fresh state was poured into the remaining volume to create bond between the two materials in the cylinder. The standard cylindrical mold of 6 in $\times 12$ in $(152.4 \mathrm{~mm} \times 304.8 \mathrm{~mm})$ was used. The asphalt concrete cylindrical samples were molded and compacted in a 6in $\times 6$ in $(152.4 \mathrm{~mm} \times 152.4 \mathrm{~mm})$ cylinder using a gyratory compactor (Roberts et al., 1996). The cylindrical samples were cured for 7 days at moisture room conditions. The composite cylinders were cut into several pieces (perpendicular to the cylinder's axis). Each piece was cut diagonally at the angle of $90^{\circ}$ $\delta$ from the AC/PCC interface ( $\delta$ is the crack inclination angle, shown in Fig. 1 ) to make the final BSCB specimens. A crack length ratio of $\mathrm{a} / \mathrm{R}=0.5$ was selected. For creating the cracks, first a cutting machine is used to generate a notch through the interface with the initial depth of slightly less than $38.1 \mathrm{~mm}$. Then, a sharp pre-crack was introduced by a thinner blade cutter to make the final length of each crack. 
The interface cracks are generated at different inclination angles $(\delta)$ to be used for different mixed mode fracture tests as listed in Table 1. A total number of 50 BSCB specimens were made for five mixed mode conditions and at two test temperatures. That means five BSCB specimens were prepared for each mode mixity.
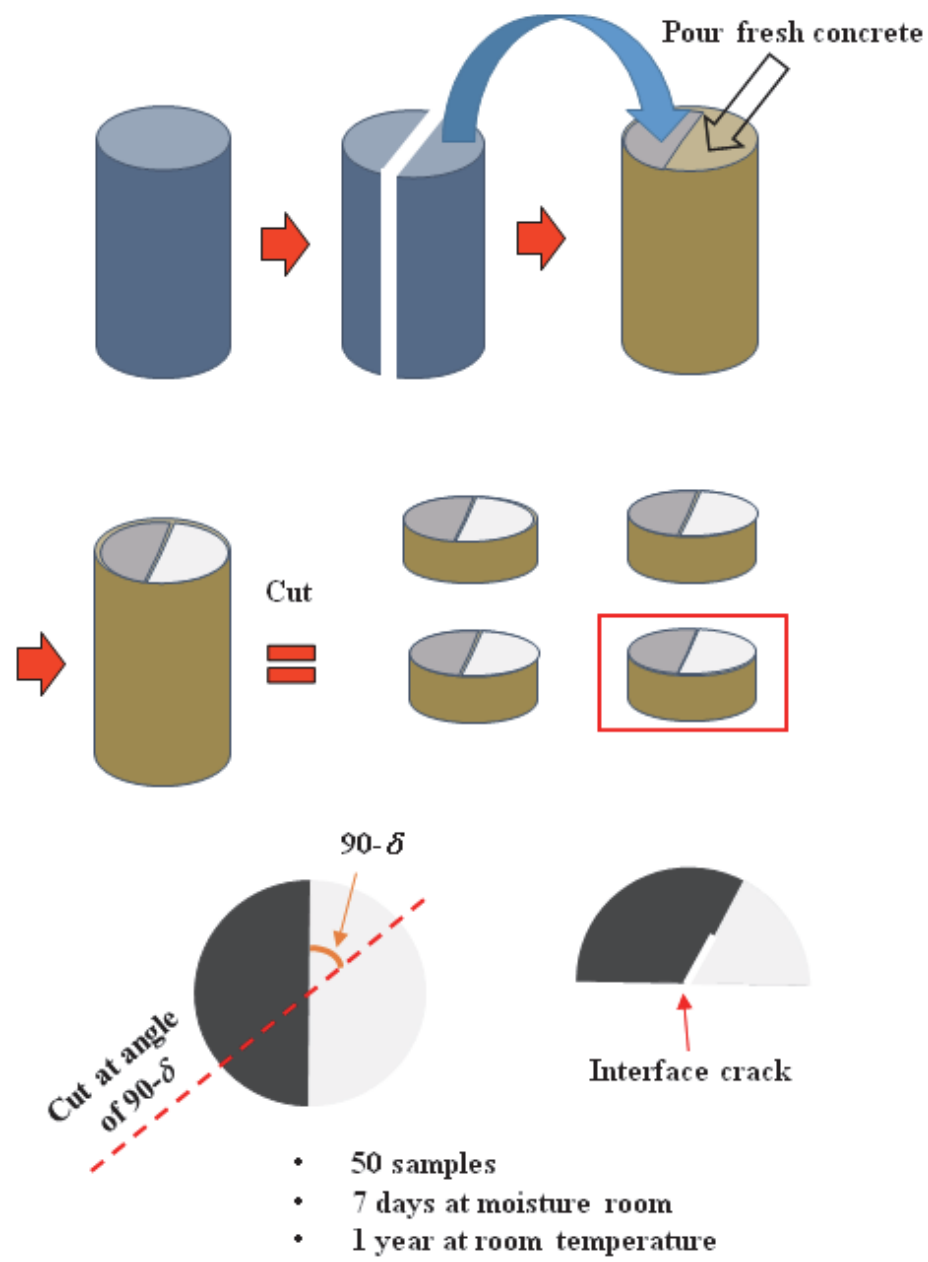

Fig. 4. Preparation of BSCB specimens made of AC and PCC

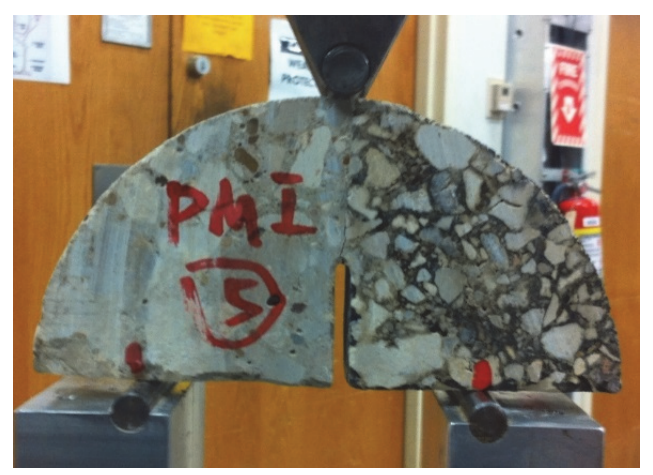

Fig. 5. Loading set up for a typical BSCB specimen

\section{Fracture tests}

Each BSCB specimen was positioned inside a three-point bend loading fixture with desired values of S1 and S2, and loaded at the constant rate of $0.4 \mathrm{~mm} / \mathrm{min}$ up to its final fracture. Fracture tests were conducted at two temperatures: $20^{\circ} \mathrm{C}$ (room temperature) and $-20^{\circ} \mathrm{C}$ in order to investigate effect of pavement temperature on the bond strength between layers. All the test samples fractured from the interface crack tip and with negligible non-linear deformation before debonding.

Fig. 5 shows the loading set up for one of the BSCB specimens and a sample fractured specimen. Using the fracture load obtained from each specimen, the critical stress intensity factors of the tested BSCB specimens were calculated from equations 1 and 2. Details of each test including, the fracture loads and the corresponding stress intensity factors are listed in Tables 4 and 5 for $\mathrm{T}=-20^{\circ} \mathrm{C}$, and $\mathrm{T}=$ $20^{\circ} \mathrm{C}$, respectively. In Tables 4 and 5, the specimen codes are PMI: pure mode I, PMII: pure mode II, 
MM-I: mixed mode type I $(\mathrm{S} 1=30 \mathrm{~mm}, \mathrm{~S} 2=20 \mathrm{~mm}), \mathrm{MM}-\mathrm{II}$ : mixed mode type $\mathrm{II}(\mathrm{S} 1=60 \mathrm{~mm}$, $\mathrm{S} 2=15 \mathrm{~mm}), \mathrm{MM}-\mathrm{III}:$ mixed mode type III $(\mathrm{S} 1=\mathrm{S} 2=50 \mathrm{~mm})$.

Table 4. Summary of the results obtained from mixed mode I/II fracture tests conducted on BSCB specimens made of $\mathrm{AC} / \mathrm{PCC}$, at $\mathrm{T}=-20^{\circ} \mathrm{C}$

\begin{tabular}{llll}
\hline Specimen code & $F_{c r}(N)$ & $K_{I}(\mathrm{MPa} \sqrt{m})$ & $K_{I I}(\mathrm{MPa} \sqrt{m})$ \\
\hline PMI-1 & 3207 & 0.0941 & 0 \\
PMI-2 & 3461 & 0.1015 & 0 \\
PMI-3 & 3420 & 0.1003 & 0 \\
PMI-4 & 2823 & 0.0828 & 0 \\
PMI-5 & 2684 & 0.0787 & 0.0329 \\
MM-I-1 & 5850 & 0.0818 & 0.0323 \\
MM-I-2 & 5740 & 0.0803 & 0.0299 \\
MM-I-3 & 5310 & 0.0742 & 0.0337 \\
MM-I-4 & 5990 & 0.0838 & 0.0344 \\
MM-I-5 & 6120 & 0.0856 & 0.0474 \\
MM-II-1 & 4354 & 0.0589 & 0.0438 \\
MM-II-2 & 4020 & 0.0544 & 0.0458 \\
MM-II-3 & 4200 & 0.0569 & 0.0507 \\
MM-II-4 & 4654 & 0.0630 & 0.0429 \\
MM-II-5 & 3940 & 0.0533 & 0.0436 \\
MM-III-1 & 0.0297 & 0.0454 \\
MM-III-2 & 3120 & 0.0309 & 0.0503 \\
MM-III-3 & 3250 & 0.0343 & 0.0523 \\
MM-III-4 & 3600 & 0.0357 & 0.0532 \\
MM-III-5 & 3740 & 0.0363 & 0.0521 \\
PMII-1 & 3810 & 0 & 0.0506 \\
PMII-2 & 5741 & 0 & 0.0475 \\
PMII-3 & 5570 & 0 & 0.0547 \\
PMII-4 & 5231 & 0 & 0.050942 \\
PMII-5 & 6020 & &
\end{tabular}

Table 5. Summary of the results obtained from mixed mode I/II fracture tests conducted on BSCB specimens made of $\mathrm{AC} / \mathrm{PCC}$, at $\mathrm{T}=20^{\circ} \mathrm{C}$

\begin{tabular}{llll}
\hline Specimen code & $F_{c r}(N)$ & $K_{I}(\mathrm{MPa} \sqrt{m})$ & $K_{I I}(\mathrm{MPa} \sqrt{m})$ \\
\hline PMI-1 & 1120 & 0.03285 & 0 \\
PMI-2 & 1040 & 0.0305 & 0 \\
PMI-3 & 990 & 0.0290 & 0 \\
PMI-4 & 889 & 0.0261 & 0 \\
PMI-5 & 1201 & 0.0352 & 0.0111 \\
MM-I-1 & 1980 & 0.0277 & 0.0102 \\
MM-I-2 & 1820 & 0.0254 & 0.0099 \\
MM-I-3 & 1760 & 0.0246 & 0.0105 \\
MM-I-4 & 1870 & 0.0261 & 0.0094 \\
MM-I-5 & 1680 & 0.0235 & 0.0155 \\
MM-II-1 & 1420 & 0.0192 & 0.0149 \\
MM-II-2 & 1370 & 0.0185 & 0.0173 \\
MM-II-3 & 1590 & 0.0215 & 0.0143 \\
MM-II-4 & 1310 & 0.0177 & 0.0132 \\
MM-II-5 & 1210 & 0.0164 & 0.0141 \\
MM-III-1 & 1010 & 0.0096 & 0.0152 \\
MM-III-2 & 1090 & 0.0104 & 0.0185 \\
MM-III-3 & 1320 & 0.0126 & 0.0169 \\
MM-III-4 & 0.0115 & 0.0159 \\
MM-III-5 & 1210 & 0.0109 & 0.0183 \\
PMII-1 & 1140 & 0 & 0.0179 \\
PMII-2 & 2010 & 0 & 0.0168 \\
PMII-3 & 1980 & 0 & 0.01728 \\
PMII-4 & 1850 & 0 & 0.01618 \\
PMII-5 & 1897 & 0 & \\
\hline
\end{tabular}




\section{Fracture criterion}

Almost in all fracture tests, the interface crack propagated through the interface which means the bond behavior between AC and PCC can be characterized as a weak bond. The results for mixed mode interfacial fracture resistance of weak bonds are usually presented in a normalized form as $\left(K_{I I}\right)_{C} / K_{I I C}$ versus $\left(K_{I}\right)_{C} / K_{I C}$, and the fracture criterion for such weak bonds can be given as (Choupani, 2008):

$$
\left[\frac{\left(K_{I}\right)_{C}}{K_{I C}}\right]^{2 p}+\left[\frac{\left(K_{I I}\right)_{C}}{K_{I I C}}\right]^{2 q}=1
$$

where $\left(\mathrm{K}_{\mathrm{I}}\right)_{\mathrm{C}}$ and $\left(\mathrm{K}_{\mathrm{II}}\right)_{\mathrm{C}}$ are the mode I and mode II stress intensity factors at fracture, $\mathrm{K}_{\mathrm{IC}}$ and $\mathrm{K}_{\mathrm{IIC}}$ are the critical fracture toughness for pure modes, and $\mathrm{p}$ and $\mathrm{q}$ are exponents. The equation 3 can also be represented in term of fracture energies since $K_{I}=\sqrt{E^{*} \cdot G_{I}}$ and $K_{I I}=\sqrt{E^{*} \cdot G_{I I}}$, where $E^{*}=E$ for plane stress conditions and $E^{*}=E /\left(1-v^{2}\right)$ for plane strain conditions.

According to the results given in Tables 4 and 5, the averages value of mode I interfacial fracture toughness $K_{I C}$ obtained from the fracture tests (i.e. $\mathrm{S} 1=50 \mathrm{~mm}, \mathrm{~S} 2=38 \mathrm{~mm}$ ) were $0.0915 \mathrm{MPa} \sqrt{\mathrm{m}}$ and $0.0307 \mathrm{MPa} \sqrt{\mathrm{m}}$, at $\mathrm{T}=-20^{\circ} \mathrm{C}$ and $\mathrm{T}=20^{\circ} \mathrm{C}$, respectively. Also, the average value of the mode II interfacial fracture toughness $K_{I I C}$ obtained from the fracture tests were $0.0511 \mathrm{MPa} \sqrt{\mathrm{m}}$ and 0.0173 $M P a \sqrt{m}$, at $\mathrm{T}=-20^{\circ} \mathrm{C}$ and $\mathrm{T}=20^{\circ} \mathrm{C}$, respectively.

The mixed mode test results obtained in this research for various combinations of mode I and mode II are shown in Figs 6 and 7 in a $\left(K_{I I}\right)_{C} / K_{I I C}-\left(K_{I}\right)_{C} / K_{I C}$ diagram, for $\mathrm{T}=-20^{\circ} \mathrm{C}$, and $\mathrm{T}=20^{\circ} \mathrm{C}$, respectively. Also shown in these figures, the power law criterion needs $2 p=2.71,2 q=2.25$ to meet the fracture test data at $\mathrm{T}=-20^{\circ} \mathrm{C}$ and requires $2 \mathrm{p}=2.45,2 \mathrm{q}=2.15$ for $\mathrm{T}=20^{\circ} \mathrm{C}$.

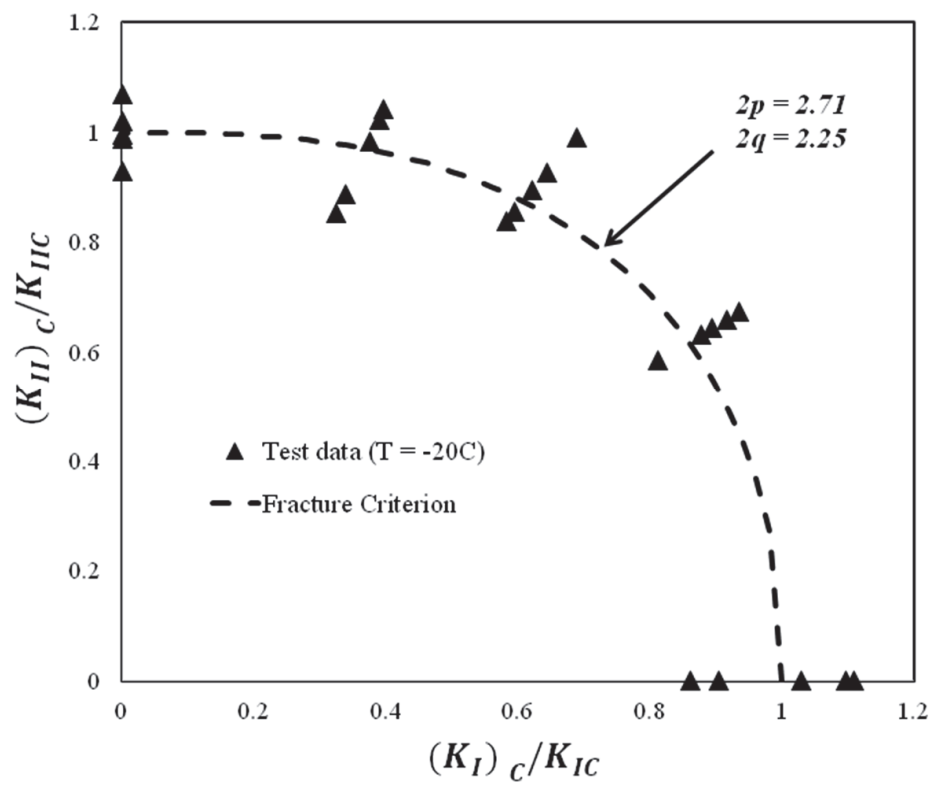

Fig. 6. Mixed-mode fracture envelope and predictions for AC/ PCC interfacial delamination at $\mathrm{T}=-20^{\circ} \mathrm{C}$ 


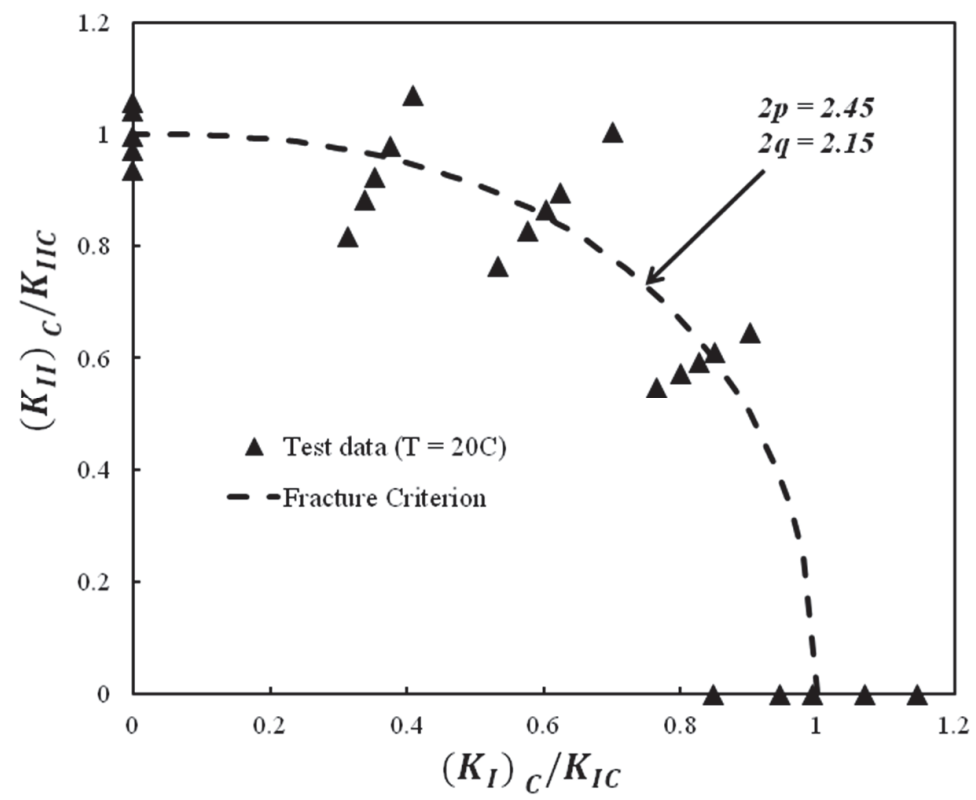

Fig. 7. Mixed-mode fracture envelope and predictions for AC/ PCC interfacial delamination at $\mathrm{T}=+20^{\circ} \mathrm{C}$

\section{Conclusions}

A new test configuration, called the bi-material semi-circular bend (BSCB) specimen, was suggested for mixed mode I/II fracture tests. A review of the test specimens suggested in the past for conducting mixed mode fracture tests shows that some of these specimens require a complicated test set up and are difficult to carry out. For instance, a biaxial fixture not only makes the test more expensive but also may be a source of error in the test results due to possible specimen manufacturing incompatibilities. The BSCB specimen suggested in this paper can be directly tested by an ordinary three-point bend fixture which is normally available in standard fracture testing machines. Furthermore, the application of compressive loads in the BSCB experiments makes it more suitable for conducting fracture tests on weak bonded interfaces. The simple geometry and loading set up, the ease of generating a crack in the specimen, and the ability of introducing a range of combinations of mode I and mode II are the main advantages of the BSCB specimen. Although almost all of the mixed mode test specimens can be used for pure mode I and mixed mode fracture tests, some of them are not able to provide pure mode II. This issue becomes even more important for a bi-material system since not only the geometry, but also the elastic properties of each material control the mode mixity. Because of the advantages elaborated above, the BSCB specimen can be recommended as a promising specimen for conducting mixed mode interfacial fracture tests. The mixed mode interfacial bond strength between $\mathrm{AC} / \mathrm{PCC}$ was successfully evaluated using the BSCB specimens at two temperatures. The effect of test temperature on the mixed mode bond strength between the AC and PCC was evaluated. It can be shown easily by a direct comparison between Figs 6 and 7, that mixed mode fracture toughness is higher at $-20 \mathrm{C}$ than $+20 \mathrm{C}$ which means a stronger bond for a more brittle bond.

\section{References}

Abd-Elhady, A. (2013). Mixed mode I/II stress intensity factors through the thickness of disc type specimens. Engineering Solid Mechanics, 1(4), 119-128.

Al-Hdabi, A., Al Nageim, H., \& Seton, L. (2014). Performance of gap graded cold asphalt containing cement treated filler. Construction and Building Materials, 69, 362-369.

Alhasan, A. A. (2013). Low Temperature Characterization of Foamed Warm Mix Asphalt (Doctoral dissertation, University of Akron). 
Aliha, M. R. M., Ayatollahi, M. R., \& Pakzad, R. (2008). Brittle fracture analysis using a ring-shape specimen containing two angled cracks. International Journal of Fracture, 153(1), 63.

Aliha, M. R. M., Ayatollahi, M. R., \& Kharazi, B. (2009). Numerical and Experimental Investigations of Mixed Mode Fracture in Granite Using Four-Point-Bend Specimen. Damage and fracture mechanics, 275-283.

Aliha, M. R. M., Heidari-Rarani, M., Shokrieh, M. M., \& Ayatollahi, M. R. (2012). Experimental determination of tensile strength and K (IC) of polymer concretes using semi-circular bend(SCB) specimens. Structural Engineering and Mechanics, 43(6), 823-833.

Aliha, M. R. M., \& Ayatollahi, M. R. (2013). Two-parameter fracture analysis of SCB rock specimen under mixed mode loading. Engineering Fracture Mechanics, 103, 115-123.

Aliha, M. M., Behbahani, H., Fazaeli, H., \& Rezaifar, M. H. (2014). Study of characteristic specification on mixed mode fracture toughness of asphalt mixtures. Construction and Building Materials, 54, 623-635.

Aliha, M. R. M., Fazaeli, H., Aghajani, S., \& Nejad, F. M. (2015a). Effect of temperature and air void on mixed mode fracture toughness of modified asphalt mixtures. Construction and Building Materials, 95, 545-555.

Aliha, M. R. M., Bahmani, A., \& Akhondi, S. (2015b). Determination of mode III fracture toughness for different materials using a new designed test configuration. Materials \& Design, 86, 863-871.

Aliha, M. R. M., Bahmani, A., \& Akhondi, S. (2015c). Numerical analysis of a new mixed mode I/III fracture test specimen. Engineering Fracture Mechanics, 134, 95-110.

Aliha, M. R. M., \& Bahmani, A. (2017). Rock Fracture Toughness Study Under Mixed Mode I/III Loading. Rock Mechanics and Rock Engineering, 50(7), 1739-1751.

Aliha, M. R. M., \& Fattahi Amirdehi, H. R. (2017). Fracture toughness prediction using Weibull statistical method for asphalt mixtures containing different air void contents. Fatigue \& Fracture of Engineering Materials \& Structures, 40(1), 55-68.

Ambati, M., Gerasimov, T., \& De Lorenzis, L. (2015). A review on phase-field models of brittle fracture and a new fast hybrid formulation. Computational Mechanics, 55(2), 383-405.

Ameri, M., Mansourian, A., Pirmohammad, S., Aliha, M. R. M., \& Ayatollahi, M. R. (2012). Mixed mode fracture resistance of asphalt concrete mixtures. Engineering Fracture Mechanics, 93, 153167.

Ameri, M., Nowbakht, S., Molayem, M., \& Aliha, M. R. M. (2016). Investigation of fatigue and fracture properties of asphalt mixtures modified with carbon nanotubes. Fatigue \& fracture of engineering materials \& structures, 39(7), 896-906.

Arabi, H., Mirsayar, M. M., Samaei, A. T., \& Darandeh, M. (2013). Study of characteristic equation of the elastic stress field near bimaterial notches. Strength of Materials, 45(5), 598-606.

Awaji, H., \& Sato. S. (1978). Combined mode fracture toughness measurement by the disc test. Journal of Engineering Materials and Technology, 100, 175-182.

Ayatollahi, M. R., Mirsayar, M. M., \& Nejati, M. (2010a). Evaluation of first non-singular stress term in bi-material notches. Computational Materials Science, 50(2), 752-760.

Ayatollahi, M. R., Nejati, M., \& Mirsayar, M. M. (2010b). An overdeterministic method for stress analysis of bi-material corners and interface cracks using finite element method. In Proceedings of the 9th Conference of Iranian Aerospace Society, Tehran, Iran.

Ayatollahi, M. R., \& Mirsayar, M. M. (2011). Kinking angles for interface cracks. Procedia Engineering, 10, 325-329.

Ayatollahi, M. R., Mirsayar, M. M., \& Dehghany, M. (2011). Experimental determination of stress field parameters in bi-material notches using photoelasticity. Materials \& Design, 32(10), 49014908.

Ayatollahi, M.R., Aliha, M.R.M., \& Hasani, M.M. (2006). Mixed mode brittle fracture in PMMA - an experimental study using SCB specimens. Materials Science and Engineering A, 417(12), 348-356.

Ayatollahi, M. R., Dehghany, M., \& Mirsayar, M. M. (2013). A comprehensive photoelastic study for mode I sharp V-notches. European Journal of Mechanics-A/Solids, 37, 216-230.

Bahmani, A., Aliha, M. R. M., \& Berto, F. (2017). Investigation of fracture toughness for a polycrystalline graphite under combined tensile-tear deformation. Theoretical and Applied Fracture Mechanics. https://doi.org/10.1016/j.tafmec.2017.02.011 
Chandra Kishen, J.M., \& Singh, K.D. (2001). Stress intensity factors based fracture criteria for kinking and branching of interface crack: application to dams. Engineering Fracture Mechanics, 68(2), 201219.

Charalambides, P. G., Lund, J., Evans, A. G., \& McMeeking, R. M. (1989). A test specimen for determining the fracture resistance of bimaterial interfaces. Journal of Applied Mechanics, 56(1), 77-82.

Chaudhuri, R.A., \& Chiu, S.H.J. (2007). Three-dimensional asymptotic stress field at the front of an unsymmetric bimaterial wedge associated with matrix cracking or fiber break. Composite Structures, $78(2), 254-263$.

Choupani, N. (2008). Mixed-mode cohesive fracture of adhesive joints: experimental and numerical studies. Engineering fracture mechanics, 75(15), 4363-4382.

Dehghany, M., Saeidi Googarchin, H., \& Aliha, M. R. M. (2017). The role of first non-singular stress terms in mixed mode brittle fracture of V-notched components: an experimental study. Fatigue \& Fracture of Engineering Materials \& Structures, 40(4), 623-641.

Dunn, M. L., Cunningham, S. J., \& Labossiere, P. E. (2000). Initiation toughness of silicon/glass anodic bonds. Acta Materialia, 48(3), 735-744.

Erdogan, F., \& Sih, G. C. (1963). On the crack extension in plates under plane loading and transverse shear. Journal of Basic Engineering, 85, 525-527.

Evans, A. G., Dalgleish, B. J., He, M., \& Hutchinson, J. W. (1989). On crack path selection and the interface fracture energy in bimaterial systems. Acta Metallurgica, 37(12), 3249-3254.

Fakhri, M., Amoosoltani, E., \& Aliha, M. R. M. (2017). Crack behavior analysis of roller compacted concrete mixtures containing reclaimed asphalt pavement and crumb rubber. Engineering Fracture Mechanics, 180, 43-59.

Fett, T., Gerteisen, G., Hahnenberger, S., Martin, G., \& Munz, D. (1995). Fracture tests for ceramics under mode-I, mode-II and mixed-mode loading. Journal of the European Ceramic Society, 15, 307-312.

Heidari-Rarani, M., Aliha, M. R. M., Shokrieh, M. M., \& Ayatollahi, M. R. (2014). Mechanical durability of an optimized polymer concrete under various thermal cyclic loadings-An experimental study. Construction and Building Materials, 64, 308-315.

Lazzarin, P., \& Zambardi, R. (2001). A finite-volume-energy based approach to predict the static and fatigue behavior of components with sharp V-shaped notches. International journal of fracture, 112(3), 275-298.

Li, X., \& Marasteanu, M. O. (2005). Cohesive modeling of fracture in asphalt mixtures at low temperatures. International Journal of Fracture, 136, 285-308.

Lim, I.L., Johnston, I.W., Choi, S.K., \& Boland, J.N. (1994). Fracture testing of a soft rock with semicircular specimens under three-point bending, part 2 - mixed mode. International Journal of Rrock Mechanics and Mining Sciences and Geomechanics Abstracts, 31(3), 199-212.

Maiti, S. K., \& Smith, R. A. (1983). Comparison of the criteria for mixed mode brittle fracture based on the preinstability stress-strain field Part I: Slit and elliptical cracks under uniaxial tensile loading. International Journal of Fracture, 23(4), 281-295.

Miehe, C., Hofacker, M., Schaenzel, L. M., \& Aldakheel, F. (2015). Phase field modeling of fracture in multi-physics problems. Part II. Coupled brittle-to-ductile failure criteria and crack propagation in thermo-elastic-plastic solids. Computer Methods in Applied Mechanics and Engineering, 294, 486-522.

Mirlohi, S., \& Aliha, M. (2013). Crack growth path prediction for the angled cracked plate using higher order terms of Williams series expansion. Engineering Solid Mechanics, 1(3), 77-84.

Mirsayar, M. (2013). Calculation of stress intensity factors for an interfacial notch of a bi-material joint using photoelasticity. Engineering Solid Mechanics, 1(4), 149-153.

Mirsayar, M., \& Samaei, A. (2013). Photoelastic study of bi-material notches: Effect of mismatch parameters. Engineering Solid Mechanics, 1(1), 21-26.

Mirsayar, M. M. (2014a). On fracture of kinked interface cracks-the role of T-stress. Materials and Design, 61, 117-123. 
Mirsayar, M. (2014b). A new mixed mode fracture test specimen covering positive and negative values of T-stress. Engineering Solid Mechanics, 2(2), 67-72.

Mirsayar, M. (2014c). A modified maximum tangential stress criterion for determination of the fracture toughness in bi-material notches-Part 1: Theory. Engineering Solid Mechanics, 2(4), 277-282.

Mirsayar, M., \& Samaei, A. (2014). Application of maximum tangential stress criterion in determination of fracture initiation angles of silicon/glass anodic bonds. Engineering Solid Mechanics, 2(3), 145-150.

Mirsayar, M.M., Aliha, M.R.M., \& Samaei, A.T. (2014). On fracture initiation angle near bi-material notches - Effect of first non-singular stress term, Engineering Fracture Mechanics, 119, 124 -131.

Mirsayar, M. M. (2015a). Mixed mode fracture analysis using extended maximum tangential strain criterion. Materials \& Design, 86, 941-947.

Mirsayar, M. M. (2015b). Three dimensional investigation of mode I stress intensity factor variations in crack front using finite element method. American Journal of Engineering and Applied Sciences, $8(1), 11$.

Mirsayar, M. M., \& Park. P. (2015). The role of T-stress on kinking angle of interface cracks. Materials and Design, 80, 12-19.

Mirsayar, M., \& Samaei, A. (2015). A finite element study on the fracture initiation at the zirconia/veneer interface: An application in dental materials. Engineering Solid Mechanics, 3(4), 207-214.

Mirsayar, M. M., \& Park, P. (2016a). Modified maximum tangential stress criterion for fracture behavior of zirconia/veneer interfaces. Journal of the mechanical behavior of biomedical materials, 59, 236-240.

Mirsayar, M. M., \& Park, P. (2016b). Mixed mode brittle fracture analysis of high strength cement mortar using strain-based criteria. Theoretical and Applied Fracture Mechanics, 86, 233-238.

Mirsayar, M. M., Berto, F., Aliha, M. R. M., \& Park, P. (2016a). Strain-based criteria for mixed-mode fracture of polycrystalline graphite. Engineering Fracture Mechanics, 156, 114-123.

Mirsayar, M. M., Huang, K., \& Zollinger, D. G. (2016b). New approach to determining concrete slab lift-off by use of interfacial fracture mechanics concepts. Transportation Research Record: Journal of the Transportation Research Board, 2590, 10-17.

Mirsayar, M., \& Takabi, B. (2016). Fracture of underwater notched structures. Engineering Solid Mechanics, 4(2), 43-52.

Mirsayar, M.M. (2017). On fracture analysis of dental restorative materials under combined tensileshear loading, Theoretical and Applied Fracture Mechanics, doi: http://dx.doi.org/10.1016/j.tafmec. 2017.07.020

Mirsayar, M. M., Joneidi, V. A., Petrescu, R. V. V., Petrescu, F. I. T., \& Berto, F. (2017a). Extended MTSN criterion for fracture analysis of soda lime glass. Engineering Fracture Mechanics, 178, 5059.

Mirsayar, M. M., Razmi, A., \& Berto, F. (2017b). Tangential strain-based criteria for mixed-mode I/II fracture toughness of cement concrete. Fatigue \& Fracture of Engineering Materials \& Structures.

Mousavi, A., \& Aliha, M. (2016). Determination of fracture parameters for a bi-material center cracked plate subjected to biaxial loading using FEOD method. Engineering Solid Mechanics, 4(3), 117124.

Razavi, S. M. J., Aliha, M. R. M., \& Berto, F. (2017). Application of an average strain energy density criterion to obtain the mixed mode fracture load of granite rock tested with the cracked asymmetric four-point bend specimens. Theoretical and Applied Fracture Mechanics.

Razmi, A., \& Mirsayar, M. M. (2017). On the mixed mode I/II fracture properties of jute fiberreinforced concrete. Construction and Building Materials, 148, 512-520.

Roberts, F. L., Kandhal, P. S., Brown, E. R., Lee, D. Y., \& Kennedy, T. W. (1996). Hot mix asphalt materials, mixture design and construction.

Sih, G. C., \& Macdonald, B. (1974). Fracture mechanics applied to engineering problems-strain energy density fracture criterion. Engineering Fracture Mechanics, 6(2), 361-386.

Suresh, S., Shih, C.F., Morrone, A., \& O-Dowd, N.P. (1990). Mixed-mode fracture toughness of ceramic materials. Journal of the American Ceramic Society, 73(5), 1257-1267. 
Theocaris, P.S. (1984). A higher-order approximation for the T criterion of fracture in biaxial fields. Engineering Fracture Mechanics, 19, 975-991.

Wang, H. T., Wang, G. Z., Xuan, F. Z., \& Tu, S. T. (2013). An experimental investigation of local fracture resistance and crack growth paths in a dissimilar metal welded joint. Materials and Design, $44,179-189$.

Williams, J.G., \& Ewing, P.D. (1972). Fracture under complex stress - the angled crack problem. International Journal of Fracture, 8, 441-446.

Xeidakis, G.S., Samaras, I.S., Zacharopoulos, D.A., \& Papakalitakis, G.E. (1996). Crack growth in a mixed-mode loading on marble beams under three point bending. International Journal of Fracture, 79, 197-208.

Yang, Y.Q., Dudek, H.J., \& Kumpfert, J. (1998). Interfacial reaction and stability of SCS-6 SiC/Ti25Al-10NB-3V-1MO composites. Material Science and Engineering A, 246(1-2), 213-220.

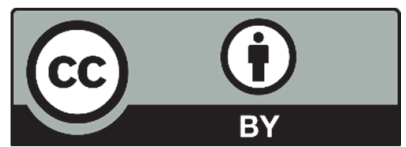

(C) 2017 by the authors; licensee Growing Science, Canada. This is an open access article distributed under the terms and conditions of the Creative Commons Attribution (CC-BY) license (http://creativecommons.org/licenses/by/4.0/). 